\title{
Decision Policy Scenarios for Just-in-Sequence Deliveries
}

\author{
Miguel Gaston Cedillo-Campos ${ }^{1}$ (i), Dario Morones Ruelas ${ }^{2}$ (D), Giovanni Lizarraga-Lizarraga ${ }^{3}$, \\ Jesus Gonzalez-Feliu ${ }^{4}$, Jose Arturo Garza-Reyes ${ }^{5}$ \\ ${ }^{1}$ National Laboratory for Transportation Systems and Logistics, Mexican Institute of Transportation (Mexico) \\ ${ }^{2}$ CEVA Logistics (Mexico) \\ ${ }^{3}$ Facultad de Ingeniería Mecánica y Eléctrica, Universidad Autónoma de Nuevo León (Mexico) \\ ${ }^{4}$ Institut Henri Fayol, École des Mines de Saint-Étienne (France) \\ ${ }^{5}$ Derby Business School, University of Derby (United Kingdom) \\ gaston.cedillo@imt.mx,dario.morones@,cevalogistics.com, \\ giovanni.lizarragalz@uanl.edu.mx, jesus.gonzalez-feliu@,cnrs.fr,J.Reyes@,derby.ac.uk.
}

Received: October 2016

Accepted: September 2017

\begin{abstract}
:
Purpose: The Just-in-Sequence (JIS) approach is evidencing advantages when controlling costs due to product variety management, and reducing the risk of disruption in sourcing, manufacturing companies and third-party logistics (3PL). This has increased its implementation in the manufacturing industry, especially in highly customized sectors such as the automotive industry. However, despite the growing interest from manufacturers, scholarly research focused on JIS still remains limited. In this context, little has been done to study the effect of JIS on the fluidity of supply chains and processes of logistics suppliers as well as providing them with a decision making tool to optimise the sequencing of their deliveries. Therefore, the aim of this paper is to propose a genetic algorithm to evaluate different decision policy scenarios to reduce risks of supply disruptions at assembly line of finished goods. Consequently, the proposed algorithm considers a periodic review of the inventory that assumes a steady demand and short response times is developed and applied.
\end{abstract}


Design/methodology/approach: Based on a literature review and real-life information, an abductive reasoning was performed and a case study application of the proposed genetic algorithm conducted in the automotive industry.

Findings: The results obtained from the case study indicate that the proposed genetic algorithm offers a reliable solution when facing variability in safety stocks that operate under assumptions such as: i) fixed costs; ii) high inventory turnover; iii) scarce previous information concerning material requirements; and iv) replenishment services as core business value. Although the results are based on an automotive industry case study, they are equally applicable to other assembly supply chains.

Originality/value: This paper is of interest to practitioners and academicians alike as it complements and supports the very limited scholarly research on JIS by providing manufacturers and 3PL suppliers competing in mass customized industries and markets, a decision support system to help decision making. Implications for the design of modern assembly supply chains are also exposed and future research streams presented.

Keywords: just-in-sequence, assembly supply chain, inventory management, automotive industry, manufacturing

\section{Introduction}

Companies in the manufacturing sector face fierce competition from industry rivals as they constantly strive to improve responsiveness to lead times and reducing costs (Staeblein \& Aoki, 2015; Esmaeilian, Behdad \& Wang, 2016). As a result, the use of operating systems based on JIT (Just-In-Time) has widely spread in order to maintain a stable inventory level (Kumar, 2010; Cedillo-Campos, Sanchez, Vadali, Villa \& Menezes, 2014; Vörös \& Rappai, 2016). In fact, the impact of JIT practices on manufacturing performance, in particular in the automotive industry, has also been the subject of a number of analyses that have proven its advantages to improve inventory management, quality, and global performance (Vörös \& Rappai, 2016; Memaria, Rahimb, Absic, Ahmad \& Hassana, 2016; Chakraborty \& Chatterjee, 2016; Green, Inman, Birouc \& Whitten, 2014; Belekoukias, Garza-Reyes \& Kumar, 2014). However, since contemporary customers now demand a greater variety of products, the increasing quantity of component variations poses a challenge for JIT-based production systems (Wagner \& Silveira-Camargos, 2011; T'kindt, 2011). Therefore, new requirements of modern manufacturing systems are pushing companies to use a novel approach, in this case known as Just-In-Sequence (JIS). 
JIS is an evolutionary progression of the JIT concept. As Werner, Kellner, Schenk and Weigert (2003) mention: "Just-in Sequence can be regarded as a refinement of the just-in-time principle that besides delivering parts at the right time, at the right place, in the right amount, and in the right quality also strives for the right sequence of the parts to be delivered". Since JIS is evidencing advantages when controlling costs due to product variety management (ElMaraghy, Schuh, ElMaraghy, Piller, Schönsleben, Tseng et al., 2013), and reducing the risk of disruption in sourcing, manufacturing companies and third-party logistics (3PLs) providers have actively started to implement it (Wagner \& Silveira-Camargos, 2011; Ludwig \& Hogg, 2016; Ludwig, 2016a, 2016b, 2016c). For instance, although JIS is a commonly deployed approach in the automotive manufacturing sector (T'kindt, 2011), it is also becoming increasingly relevant in other highly customized mass production industries such as electronics, heavy machinery, furniture and motorcycle production (Werner et al., 2013; Trebilcock, 2006; Rosendahl \& Radow, 2004). Thus, the modern business of companies providing sequencing service to the final assembly line is to guarantee short response times and driving a policy of highly controlled costs (Ludwig, 2016a; Cedillo-Campos \& Perez-Araos, 2010; Bueno \& Cedillo-Campos, 2014; Jianga, Wanga \& Yan, 2014; Suyabatmaza, Altekinb \& Şahin, 2014).

In addition, as a result of the current dynamic and complex operational environment in the manufacturing sector, the risk of production stoppages or avert transport disruptions of supply chains is increasing (Ludwig, 2016a; Bunkley, 2015; Bayara, Darmoulb, Hajri-Gabouja \& Pierreval, 2016; Zhang \& Lam, 2016). For exemple, concerning the automotive industry, the penalties for assembly line stoppages can reach values of about US $\$ 5,000$ per minute, which represents a serious financial and operational threat to any 3PL supplier. This is why modern organizations are looking to improve their supply chain fluidity. For the purpose of this paper, supply chain fluidity is understood as: "the capability degree to continuously achieve a reliable, secure and accurate flow of process, effectively supporting the supply chain goals" (Cedillo-Campos \& CedilloCampos, 2015).

Today, manufacturing, agro-food and services companies as well as ports (Braden, 2016) and railway companies (BNSF, 2016) are achieving a great revolution due to use of both JIS and supply chain fluidity as pillars of their logistics competitiveness.

In fact, delivering components based on a JIS approach contributes to achieve fluid operations in a manufacturing system and its assembly lines, mainly because of the complexity in computing in advance all the costs related to assembly operations. Due to the short transit time between the warehouse location and the production site of OEMs (i.e. car manufacturers), in-transit inventory and the stock located at every workstation of the assembly line are usually considered as "delivered to the customer" (i.e. delivered to the assembly company) in the inventory system of the 3PL suppliers. Thus, in the automotive industry, once the components leave the 3PL's warehouse, they are considered part of the inventory of the carmaker. 
However, despite the significant importance that JIS has acquired for practitioners in mass customized industries (Wagner \& Silveira-Camargos, 2011; Werner et al., 2003; Trebilcock, 2006; Rosendahl \& Radow, 2004), little attention has been paid to it in the academic literature. Especially when compared to the vast amount of research focused on the traditional JIT approach and when studied from a Supply Chain Management perspective (Wagner \& Silveira-Camargos, 2011).

In this context, Heinecke, Köber, Lepratti, Lamparter and Kunz (2012), Thun, Drücke and Silveira-Camargos (2007), Thun, Marble and Silveira-Camargos (2007), Graf (2007) and Werner et al. (2003) focused on proposing algorithms to address the sequencing problem of assembly lines. On the other hand, Hüttmeir, de Treville, Van Ackere, Monnier and Prenninger (2009), Toth, Seidel and Klingebiel (2008), Lindner (2008), Poiger and Reiner (2008) and Rosendahl and Radow (2004) documented the practical application of JIS through cases.

Furthermore, Wagner and Silveira-Camargos (2011) provided a framework to determine under which circumstances switching from JIT to JIS is more advantageous, whereas Meissner (2010) proposed systematic key performance indicators to make process instability transparent and manageable under JIS conditions. Nevertheless, and despite this limited research in the field of JIS, very little has been done to study the effect of JIS on the fluidity of supply chains.

In this line, even if sequencing is a critical process, most of the logistics providers with operations make decisions mainly based on the knowledge of their management team (Shi, Zhang, Arthanari, Liu \& Cheng, 2016). That is to say, they count on marginal technological support when making complex decisions regarding the operationalisation of JIS deliveries. To address this issue, this paper contributes to the JIS body of knowledge by providing a solution, based on genetic algorithms, to support logistics suppliers on the sequencing and delivering of their products under JIS conditions. Thus, it introduces a periodic review model for the control of inventories of sequenced material in workstations. The model allows us to evaluate different decision policy scenarios concerning four common operating policies in which most of the automotive assembly plants located in Mexico are organized. Consequently, the aim of this paper is to propose a genetic algorithm to evaluate different decision policy scenarios to contribute in increasing supply chain fluidity based on the JIS deliveries approach.

Besides its theoretical value and contribution to the JIS body of knowledge, the genetic algorithm proposed in this paper, and its results, are also of interest to manufacturing and 3PL managers as a tool to support decision-making when supplying material to an assembly line. Thus, since the proposed decision support system provides solutions in real time, it would allow manufacturers and 3PL suppliers competing in mass customized industries to improve inventory management, reduce production stoppages risk, and consequently, increase supply chain fluidity. 
Furthermore, due to the current high relevance of the mass customization strategy and its importance for many industries and organizations, other industrial sectors such as machinery (Trentin, Forza \& Perin, 2015), electronics (Doolen \& Hacker, 2005), shoes (Dietrich, Kim \& Sugunaram, 2007), apparel (Kincade, Regan \& Gibson, 2007), among others, where JIS strategy is also prevalent can also benefit from this research and the proposed genetic algorithm.

The rest of the paper is organized as follows: Section 2 describes the problem analysed. Section 3 discusses the methodology followed to conduct this research. Section 4 presents a numerical example and its results. Finally, Section 5 presents the conclusions, limitations of the research and future research agenda derived from this work.

\section{Problem Description}

Due to the increasing number in the variety of products (ElMaraghy et al., 2013), the need to reduce cost and disruption risk by delivering components following an exact sequence has gained importance in assembly-intense industries such as the automotive sector. Current customer requirements are driving production systems to mass customization, where a large variety of products and customization choices are becoming a standard strategy to increase market share. Thus, the concept of JIS as a logistics approach for directly supplying components to assembly lines has been increasingly used (Wagner \& SilveiraCamargos, 2011; Hüttmeir et al., 2009; Meissner, 2010; Wagner \& Silveira-Camargos, 2012). This is mainly because of supply chain fluidity (speed and accuracy) in which decisions must be made in the current competitive environment.

In most of the automotive assembly plants located in emerging markets such as Mexico (OICA, 2016), deliveries are organized based on a policy of periodic review of inventory levels $(s, S)$, and a delivery decision is made on the shipping manager's perception of the inventory levels at the workstations. Until now, this procedure is the "standard" when running operations under a JIS approach (Wagner \& SilveiraCamargos, 2011; Hüttmeir et al., 2009).

Currently, most of the car assembly plants in Mexico are running operations in a similar way as that described by Meissner (2010) (see Figure 1). However, there is an enormous difference. While Meissner (2010) identifies that the planned sequence for the assembly process of customized vehicles should be "frozen" some days before the actual assembly takes place, in Mexico, the "frozen" period to plan sequences are only some hours. Another difference is that in Mexico only one 3PL is in charge to deliver components and modules in sequence, from supplier's warehouses located in the near area to every workstation all along the assembly line. 
Thus, once the assembly sequence is defined by the carmaker, the "frozen" period starts, and the painting department delivers its approval (this approval indicates that the painting department, the first one, is ready to start the process), the 3PL provider is informed to deliver JIS the corresponding components. At the same instant, the bodywork enters to the paint shop, then, it continues along the painting tunnel until the painted bodywork arrives to the first workstation. Thus, the 3PL reaction time is defined by the time between it receives an order from the carmaker and the moment in which the bodywork arrives to the first workstation of the assembly line (see Figure 1). In anticipation of unexpected operational conditions, the paint shop is used as a buffer against variability or disruptions produced by delayed deliveries or other causes. Thus, sometimes, if an unforeseen event takes place, the paint shop rate is delayed to allow the 3PL provider deliver components or modules to the first assembly line workstation.

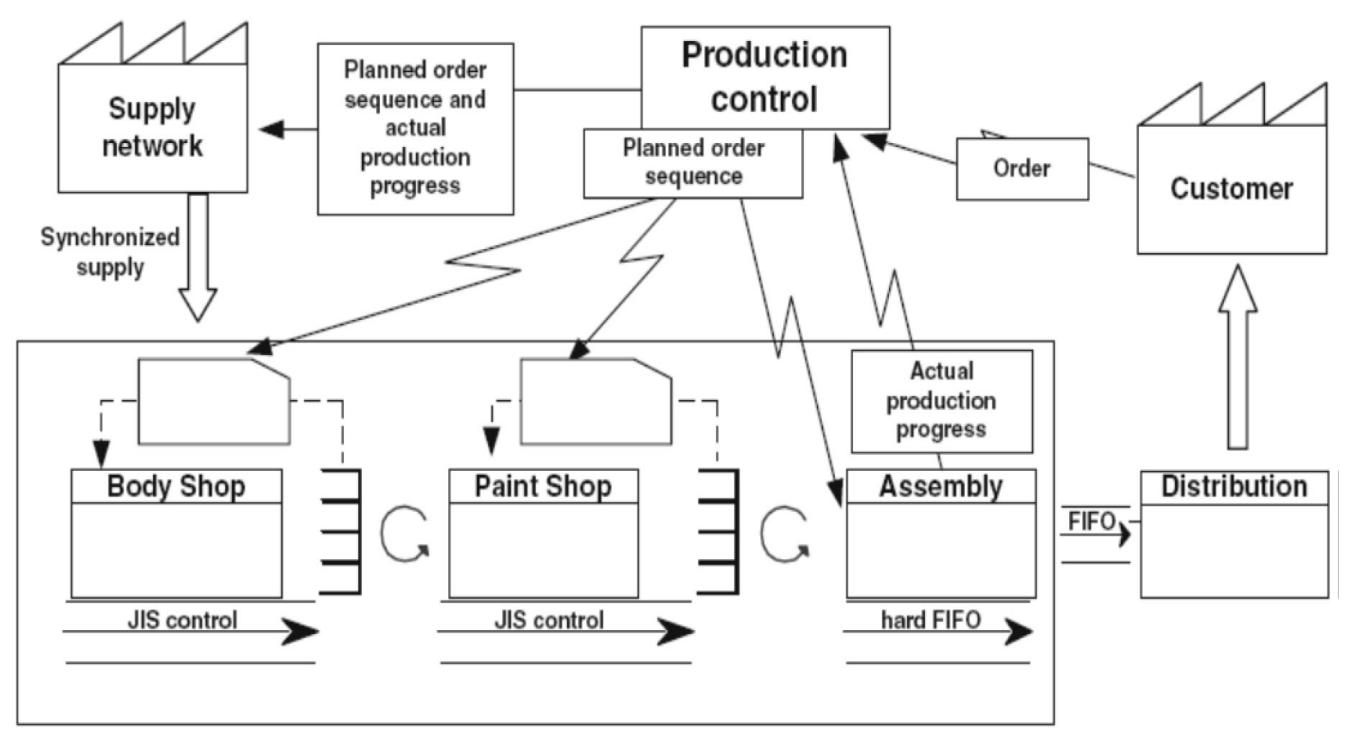

Figure 1. Vehicle flow through workstations (Meissner, 2010)

For this reason, when the number of vehicles inside the paint shop decreases, so does the reaction time available to deliver components to the workstations. In that context, 3PL's management team "synchronizes" its deliveries to the assembly line rate based on radio communication systems. As a result, delivery decisions are adjusted "on real-time" without any technical basis, just as reaction, creating more variability in the supplier's inventory. Thus, 3PL decisions increase the bullwhip effect in the system, and consequently, the risk of disruptions increases (Chiang, Lin \& Suresh, 2016). On the other hand, sometimes the assembly plant's management team creates variability in the process. For example, when the paint shop is empty, vehicles are moved as fast as the conditions allow it in order to arrive to the first workstation as soon as possible. Consequently, the reaction time to 3PL provider is also reduced. 
The mixture of models is estimated from the variety of scheduled vehicles to be produced in the assembly line, which have a discontinuous assembly sequence. However, this mixture could be altered by the inability to supply a specific model by the paint shop.

Taking into account this context, the proposed model runs based on a logic of standardization of inventory measurement units which are call: "stock cover". In this research, "stock cover" is understood as "the length of time that inventory will last if current usage continues" (KPI Library, 2016). The speed at which the assembly line runs was taken as reference. This helped us to define the "units" of stock cover remaining at the workstations. This approach allows us to reduce the complexity caused by the mixture of units.

The conversion from delivered dollies to stock cover units was computed as follows:

$$
\Phi=(X * \Psi) / \Omega
$$

Where:

$\Phi=$ Batch of stock cover assigned to a sequenced dolly;

$X=$ Number of components inside the dolly;

$\Psi=$ Demand

$\Omega=$ Mix of demanded components on the assembly line.

Since the goal was to avoid an assembly line disruption, the time required to transfer and deliver components was estimated as the lower limit of the inventory $(\gamma)$, that is to say the minimum time to place an order. It is composed by the addition of times of shipping, transport, reception and placement of an order at the workstation. This was calculated as follows:

$$
\gamma=\delta+\varepsilon+\zeta
$$

Where:

$\gamma=$ Lower limit time allowed;

$\delta=$ Transit time;

$\varepsilon=$ Shipment time.

$\zeta=$ Time of reception at the assembly plant and placement of the material in the point of use.

The upper limit $(\boldsymbol{\eta})$ is the maximum amount of units that can be received by the assembly line, and includes the units in the painting shop plus the number of workstations, from the beginning of the seats assembly line to the point of consumption minus the delivered batch. It was computed as follows: 


$$
\eta=\theta+\varkappa-((X * \xi)) / \Omega
$$

Where:

$\eta=$ Upper limit allowed;

$\theta=$ Units in the paint shop;

$\varkappa=$ Number of workstations until point of use;

$\xi=$ Demand per unit time units.

The size of each scenario ( $\varsigma$ ) was computed as follows:

$$
\varsigma=\tau / \phi
$$

Where:

$\varsigma=$ Number of components in a decision policy scenario;

$\tau=$ Total time;

$\phi=$ Review period.

Based on an abductive research approach (Kovács \& Spens, 2005; Dubois \& Gadde, 2002) we analyzed the operational conditions, and as a result, based on Morones (2011), four decision policies were defined.

Decision policy one: Deliveries of components and modules as well as production rate performs as planned. Thus, stock cover level units were computed as follows:

$$
\begin{aligned}
& S(i)=s(i-1)+\Phi \\
& s(i)=S(i)-(\xi * \phi)
\end{aligned}
$$

Where:

$S=$ Inventory level after the option of shipping;

$s=$ Inventory level before the option of shipping;

$i=\mathrm{i}$-th review period.

Decision policy two: Deliveries of components and modules fail, and consequently, production rate is also null. Accordingly, stock cover level units were computed as follows: 


$$
\begin{gathered}
S(i)=s(i-1)+\Phi \\
s(i)=S(i)
\end{gathered}
$$

Decision policy three: Deliveries of components and modules ends while production rate is finished at the end of the working day. Accordingly, stock cover level units were computed as follows:

$$
\begin{gathered}
S(i)=s(i-1) \\
s(i)=S(i)-\left(\xi^{*} \phi\right)
\end{gathered}
$$

Decision policy four: Deliveries of components and modules are in pause while production rate is also in pause, for example, during lunch and other planned stoppages. Accordingly, stock cover level units were computed as follows:

$$
s(i)=S(i)
$$

The level of inventory is review each period $\phi$, in order to decide if more components must be sent to the line of production, so the number of times where a delivery can be done is $\varsigma$ as shown if Formula 4 .

\section{Methodology}

A solution for the problem mentioned in Section 2, is a list of the times in which a new batch of components must be sent to the production line. This list is a subset of the $\varsigma$ times where a decision must be make about sending components or not. So, the size of search space for this problem is the number of subset of a set of size 5 , which is $2^{5}$. The size of the search space grows exponentially as the periods of revision get smaller. An exhaustive search can be inappropriate for large instances of this problem. Thus, genetic algorithms play an important role in solving complex mathematical problems in operations research (Kumar, Kumar, Brady, Garza-Reyes \& Simpson, 2017; Diabat \& Deskoores, 2016). Over the years, a wide range of industrial problems have been addressed through the application of a number of algorithms such as Genetic Algorithms, Particle Swarm Optimization, Ant Colony Optimization Algorithms, and Artificial Immune System and Bee Colony Optimization based algorithms (Kumar, Mishra, Chan \& Verma, 2011; Moslehi, \& Mahnam, 2011). However, in this particular case, solutions based on genetic algorithms were defined since they are able to maintain a variety of possible solutions for every decision policy scenario. In fact, genetic algorithms find high quality solutions by selecting the best solution in each interaction (Chen, 
Chen \& Liang, 2016; Gunner, Tunali \& Jans, 2010; Pelikan, 2010; Saracoglua, Topaloglub \& Keskinturk, 2014).

Thus, in order to create a model of the problem described in the previous section, several considerations were made. It was found that the best decision policy scenario was that whose deviation from the average desired inventory level is the smallest. It is important to highlight that the inventory level can only be increased with defined batches of shipments and when there is continuous demand. In this paper, based on Benkherouf and Sethi (2010), we defined an objective function to minimize:

$$
\text { Minimize } Z=\sqrt{\frac{\sum_{i=1}^{n}\left(8-Q_{i}(x)\right)^{2}}{n-2}}
$$

Where:

$Q_{i}(x)=$ Inventory level;

$b=$ Desired average inventory level;

$n=$ Total inventory elements $S$ and $s$

$x=$ Vector of decision variables.

The search variables $x$ is a string of binary variables defined as follows: suppose that we want to determine the decision policy scenario for the next nine hours ( $\tau$ from Equation 4$)$ and we review the inventory every 30 minutes. This means that we have 18 review periods ( $\varsigma$ from Equation 4 ), in which the level of the inventories are reviewed and the decision of sending or not sending a shipment of material is made. Therefore, for the next nine hours, 18 decisions will be made, the first decision at minute 0 , the second one at minute 30 , and so on until minute 510. If we use a string of 18 ( $\varsigma$ from Equation 4 ) binary numbers ( $x$ from Equation 12), we can represent every possible shipment schedule for the next nine hours. Each binary number can take the value of " 1 " or " 0 ", where "1" means that a shipment is sent and “0” means that no shipment is sent. For example, the string "001000100010000000" means that three shipments will be sent, the first one at minute 60 , the second one at minute 180 , and the third one at minute 300. This codification is straightforward, and can be used with any period of time and any frequency in the revision of the inventory level.

Note that a value of " 1 " in $x$ represents Policy One, when a shipment is sent, and a value of " 0 " represents Policy Three, when no shipment is sent. Policy Two and Four are not represented in $x$ because those cases always appear at the end of the working day and in the shift period. 
Depending on the value of $x$ and the initial inventory level, the inventory levels through $\tau$ will present different behaviours and different values for the objective function.

\subsection{Genetic Algorithms}

Genetic Algorithms (GA) are a paradigm of Evolutionary Computation. Other paradigms are Evolutionary Strategies, Differential Evolution and many others. GA are basically an optimization algorithm that are inspired in the Theory of Evolution of Species by Natural Selection, and takes many concepts such as mutation, the survival of the fittest, population, etc, in order to find a solution to a problem. In GA a candidate solution for a problem is coded as a vector of zeros and ones (a binary vector). A set of binary vectors is known as a population and a single vector is usually known as an individual. The elements of a population are mutated and recombined in order to obtain new vectors that represent a better solution for the problem. The vectors that are mutated and recombined are a selection of the best elements of the population. The idea is that the best elements of a population can be used to obtain new solutions that are even better than their "parents".

A fitness value is assigned to each element of the population, depending on how good is the solution that the individual represents. The method to assign a numeric value for the fitness depends on the problem. For example, in a problem where we want to minimize the travel time from one point to another point, the fitness value can be calculated the formula:

$$
F(x)=1 / T(x)
$$

Where $F(x)$ is the value of fitness value, $x$ is a solution for the problem and $T(x)$ is the travel time that results for the application of solution $x$. Note that this formula assign a greater fitness value to individuals with shortest travel time.

Once each individual of the population has a fitness value assigned, the next step of a GA is to make a selection of the best individuals in the population. This selection will be used to generate a new population through a mechanism of recombination. If the size of the population is $n$, we can take $n / 2$ individual from the population to generate the next population. There are several mechanism to make the selection. Binary tournament is one of the most popular methods. In Binary tournament, we take randomly two elements of the population, then we compare the fitness of the individuals and select the individual with the highest fitness value. This operation is repeated until the desired number of individual is achieved. 
Next, a recombination process is executed. In GA, the recombination process is the main search strategy. It is performed following way:

1. Choose randomly two individuals (Parent 1 and Parent 2).

2. Assuming that the numbers of binary number in each individual is $m$, generate a random number $k$ between 1 and $m-1$.

3. Take the first $k$ bits from Parent 1 and concatenate them with the last $m-k$ bits of Parent 2 . This concatenation generates a new individual (Offspring 1).

4. Take the first $k$ bits from Parent 2 and concatenate them with the last $m-k$ bits of Parent 1 . This concatenation generates a new individual (Offspring 2).

Note that each recombination generates two new individuals. If the size population $n$ we can perform $n / 2$ recombination in order to create a new population.

Another important operator that in GA is the mutation. Mutation consist on flipping a random bit of an individual. For each a population of size $n$, we perform the mutation with a probability $p m$. Common values for $p m$ are 0.05 or 0.01 .

The general algorithm for ES is as follows:

1. Generate an initial population randomly.

2. Evaluate the objective function for each element of the population.

3. Select the best individuals of the population.

4. Recombine the best elements of the population.

5. Mutate the recombination of the best elements of the population to create a new population.

6. Substitute the old population with the new population.

7. Repeat from step 2 until the stop criterion is reached.

The process of selecting the best individuals in a population, recombining these individual to generate offsprings, mutate the offsprings and evaluate their fitness is known as a "generation". A common stop criterion is to perform a fixed number of generations. Another stop criterion is when all the population has the same (or very similar) fitness value. At the end, the vest solution found is chosen as the solution to the problem.

Genetic algorithms has very interesting properties. They can work with non-linear problems, discrete and discontinuous problems, restricted and un-restricted problems, etc. They only need an explicit formula for 
the objective function of the problem. The disadvantage of a GA is that a lot of function evaluations are necessary to find a solution. In cases where the objective function is cheap to evaluate this is not an issue.

Note that the model presented in Section 3.A fits perfectly with a GA. All solutions can be codified as a string of binary numbers. The problem is discontinuous and the objective function is easy to evaluate. The Genetic Algorithm was implemented in Matlab. The experiments were run in computer MacBook Air Model 2014, processor $1.4 \mathrm{GHz}$ intel Core i5, 4 GB RAM. The size of population used was 400 individuals. The algorithms was run for 50 generations. The recombination probability is 0.9 and the mutation probability is 0.01 .

\section{Numerical Example and Discussion}

The proposed model was applied to sequencing operations developed by a world-class 3PL located in the Automotive Cluster Southeast Coahuila (CARSC), which is also one of the most important clusters in Mexico (Cedillo-Campos \& Gudiño, 2011; Sanchez, Cedillo-Campos, Martinez \& Perez, 2011). Specifically, the analysis was performed for the sequenced component of the vehicle " 166 ".

The system was tested in order to validate it as a decision-making tool to support material shipping. The system must be able to indicate the number of items with which the shipments staff could achieve a desired average inventory. Moreover, it was essential to reduce the error insofar as a desired average level, by evaluating the options that could obtain the least variation in shortening the time to reach the required limits to ensure supply. In this way, the normalized system frequency of shipments with the desired level of stock cover reduces the time in which they reached the required level for supply. Levels were taken from the two shifts (both in the first round). First, the shipping decisions were used based on the report of the critical required components and then on the series of decisions proposed by the system here presented (see Figures 2 and 3). We can see in Figure 2, based on the report of the critical required components that in two times, a stock cover of below 65 units was reached during the periods 14 and 15, with a prediction error calculated at 28.54 compared to the level of desired stock cover.

Since the purpose of the project was to provide a quantitative basis for decision-making, a proposal was made considering a series of shipments in 18 periods of sequenced material shipments. The behaviour followed by the level of stock cover is shown in Figure 3. One can see that the stock cover levels did not drop below 80 units, just as calculated; and with a prediction error of 14.55 compared to the stock cover level desired. 


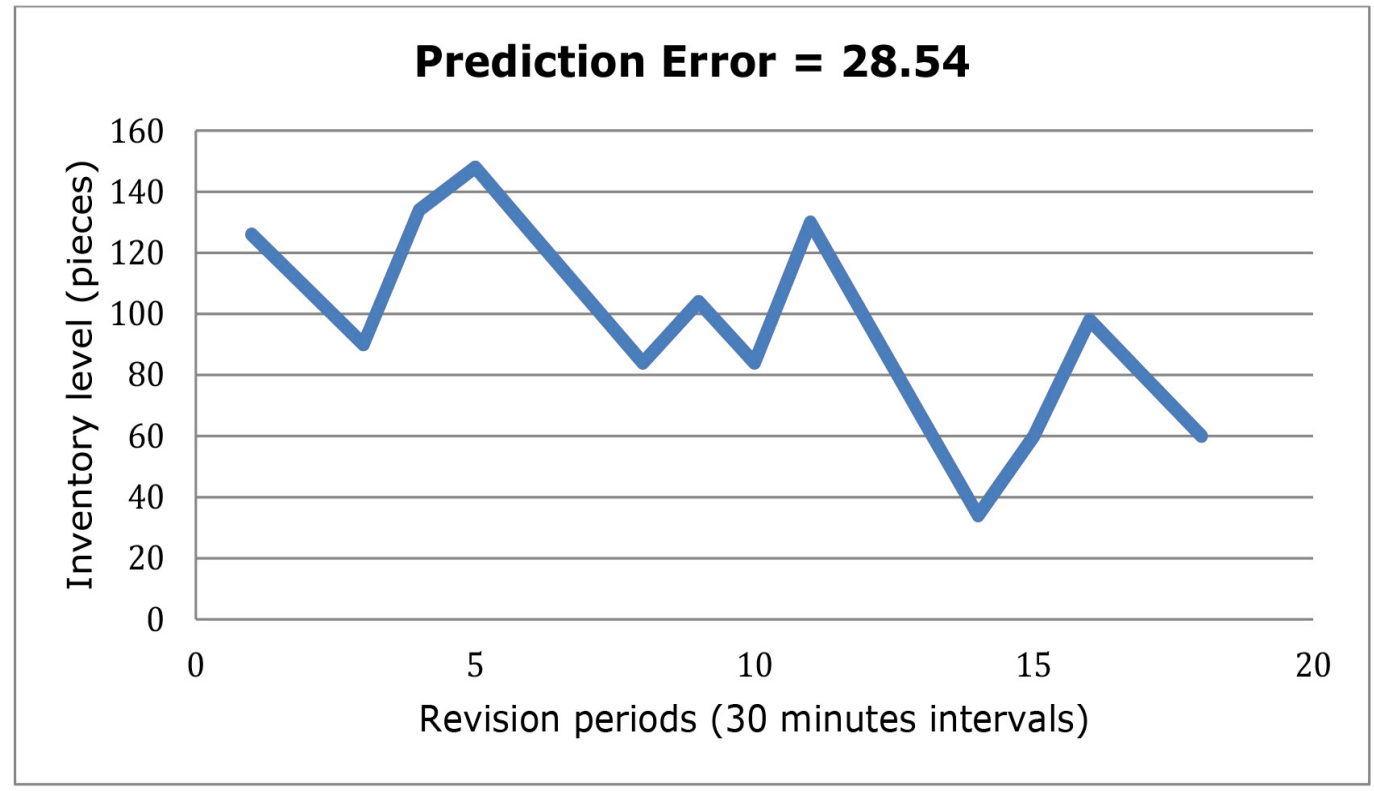

Figure 2. Inventory level based on report of the critical required components

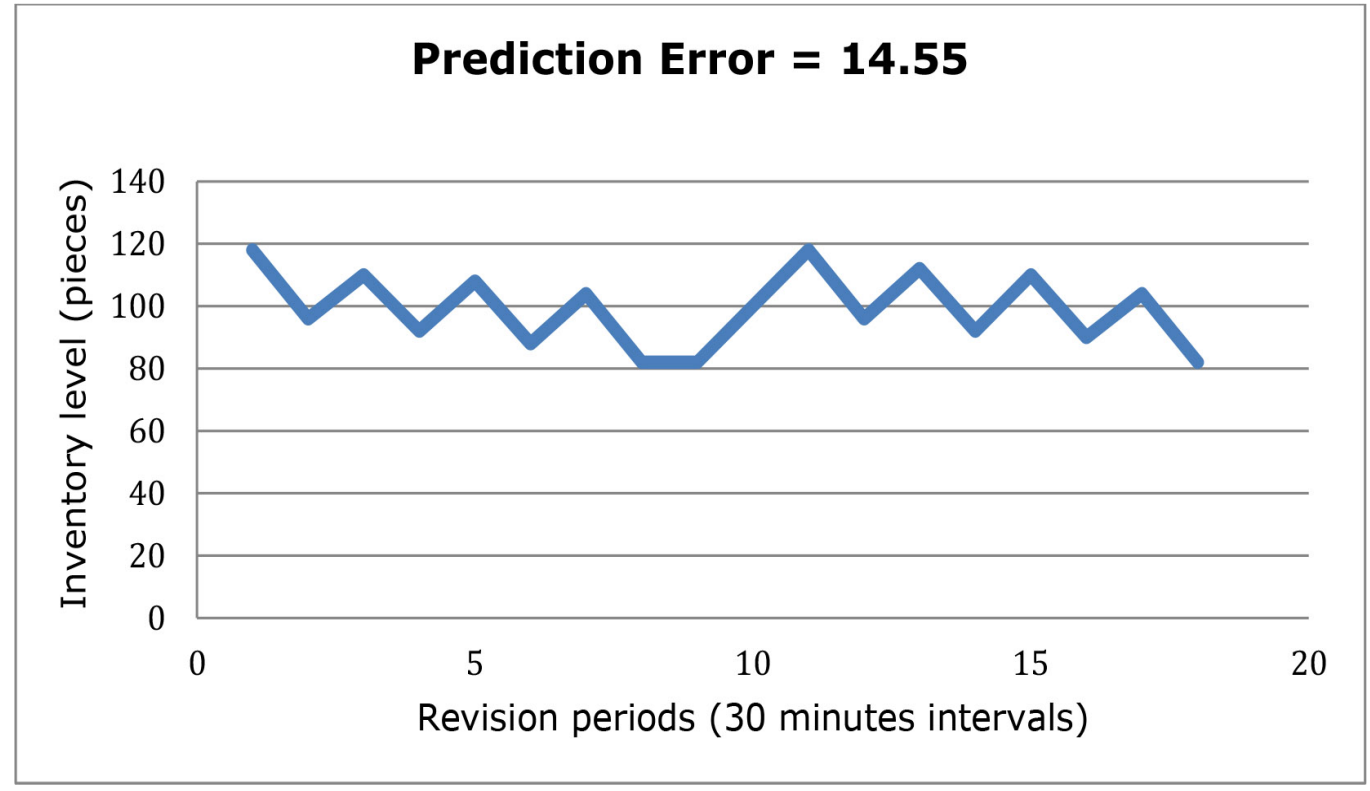

Figure 3. Inventory level based on our proposed system

The prediction errors show the average distance that exists between the stock cover level and the inventory level in each period. The inventory level that is managed by the proposed system presented a lower estimation error, which proved the existence of a minor deviation from the desired stock cover level.

The model development was focused on how to improve the delivery of sequenced material for the automotive assembly plant, considering the personnel as the main actor responsible for decision-making 
for shipments. A genetic algorithm was used to model the behaviour of the system considering the decisions made and the possible decision policy scenario.

It was proven that the algorithm could be adjusted to any period based on periodic reviews, calculating the possible decision policy scenario once again, reducing the variation from the desired stock cover level. The use of mapping in the decision-making process regarding the level of stock cover desired facilitated the obtaining of results by computing the differences between them. Moreover, by calculating the total sum of these differences, the lowest value of the differences was obtained. With this, we evaluated all the values of $\mathrm{s}, \mathrm{S}$ scenarios that were achieved. When performing a test for equality of variances, we found the statistical evidence to conclude that the model yields data with a median similar to the system data with a confidence level of $95 \%$. This allowed us to conclude that the model produces a reliable representation of the sequencing system for decision-making. Using the measured level of stock cover, the problem of the mixture is smoothed. This level covers linear units sent through without counting the physical quantities of the parts being sent.

Based on the current level of inventory, the model proposed in this paper considered the various properties possessed by each family of parts. By obtaining the number of shipments, the critical periods of demand occurring while refuelling were reduced, thereby having a better control of the resources provided. The description of the sequencing system through operating policies and the search for a ranking point helped to achieve a better adaptation to the system solution regarding the management of a policy of operating costs.

\section{Conclusions and Future Research}

This paper highlights the significance of JIS deliveries in highly competitive environments and assembly-intensive manufacturing systems, such as those traditionally found in mass customized industries, and particularly the automotive manufacturing sector. Due to contemporary customer requirements, discussion in the literature shows that there is a growing interest among the research community to explore the formulation of effective, fast and accurate customization strategies by using the JIS deliveries approach as a vehicle to achieve this. However, despite this growing interest, scholarly research in the field of JIS still remains very limited, especially when compared to the amount of research that has focused on JIT. For this reason, this paper fills a research gap as previously highlighted in Section 1 and extends the body of knowledge in the field of JIS by:

- Focusing on the effect of JIS on the fluidity of supply chains and processes of manufacturers and logistics suppliers; 
- Providing a reliable solution, based on genetic algorithms, to support logistic suppliers on the sequencing and delivering of their products under JIS conditions.

In particular, the genetic algorithm proposed offers a reliable solution when facing variability in safety stocks that operate under assumptions such as: i) fixed costs; ii) high inventory turnover; iii) scarce previous information available concerning material requirements; and iv) replenishment services as core business value. To achieve its development, different solutions were assessed, and as a result, an efficient genetic algorithm to evaluate diverse scenarios of decision was proposed.

At the same time, since the automotive supply chain is highly standardized, our results are susceptible of generalization to other industrial sectors. Since companies in the manufacturing industry face fierce competition, they are at the same time continuously improving responsiveness to customer demands and reducing costs. In that sense, our research proved the importance of JIS to improve "supply chain fluidity" in assembly-intense industries. More automotive companies located in Mexico are now improving their replenishment systems to achieve JIS. Actually, it is foreseen that JIS will be the new "El Dorado" concerning the industrial optimization process for the next decades.

Although the automotive supply chain is highly standardized, its manufacturing processes are based on different operational policies. Hence, to find a high quality solution when implementing JIS, a flexible model is needed. Based on our results, the proposed model provided high quality solutions when facing variability. Thus, since different operational industrial policies create sources of variability, the scenario analysis used here proved to be an effective approach. Furthermore, our research not only provides more information about the JIS approach itself, but also about the importance of accurately measuring them in order to control variability and their disruptive influence in supply chains performance.

These contributions are beneficial for manufacturing organizations, especially automotive manufacturers and those which require and operate a mass customization strategy. In this respect, appropriate managers in these organizations can learn from the proposed genetic algorithm and use it to evaluate different decision policy scenarios to reduce potential risks of supply disruptions at their production lines. This will contribute to the maximization of an organization's profits. Therefore, this paper does not only make an important contribution to the theory of the JIS approach but also to its industrial practice.

Limitations are at the origin of the next step of this research, thus, among the future work resulting from this research limitations are the study of factors influencing changes in a mix of vehicles on the assembly line. Similarly, another subject of interest is the control of vehicle production schedule, taking into account that the planning should ensure a lean production (i.e. three hours of safety stock). Excessive resources are currently spent to ensure the timely delivery of components. An extension of this work may be aimed at analysing the relationship between the outflow-sequenced materials with respect to the size of storage 
space required for each part that is sequenced. Similarly, with regards to the transport of material between the 3PL site and the assembly line, reliability analyses of service delivery are now required.

\section{Acknowledgements}

The authors would like to thank Flora Hammer for her comments and suggestions to improve this paper.

\section{Funding}

The authors acknowledge all the support provided by the National Council of Science and Technology of Mexico (CONACYT) throughout the National Laboratory for Transportation Systems and Logistics. At the same time, authors would like to thank the technical support provided by the Mexican Logistics and Supply Chain Association (AML) and the Mexican Institute of Transportation (IMT).

\section{References}

Bayara, N., Darmoulb, S., Hajri-Gabouja, S., \& Pierreval, H. (2016). Using immune designed ontologies to monitor disruptions in manufacturing systems. Computers in Industry, 81, 67-81.

https://doi.org/10.1016/j.compind.2015.09.004

Belekoukias, I., Garza-Reyes, J.A., \& Kumar, V. (2014). The impact of lean methods and tools on the operational performance of manufacturing organisations. International Journal of Production Research, 52(18), 5346-5366. https://doi.org/10.1080/00207543.2014.903348

Benkherouf, L., \& Sethi, S. (2010). Optimality of (s; S) policies for a stochastic inventory model with proportional and lump-sum shortage costs. Operations Research Letters, 38(4), 252-255. https://doi.org/10.1016/j.orl.2010.02.008

BNSF. (2016). Private Equipment Policy 2016. http://www.bnsf.com.mx/customers/equipment/ (Accessed: July 2016).

Braden, D. (2016). US ports set to receive millions to improve freight fluidity. Journal of Commerce, 1 July, 2016. http://www.joc.com/port-news/us-ports/us-ports-set-receive-millions-improve-freight-fluidity_20160706.html (Accessed: July 2016). 
Bueno, A., \& Cedillo-Campos, M. (2014). Dynamic impact on global supply chains performance of disruptions propagation produced by terrorist acts. Transportation Research Part E: Logistics and Transportation Review, 61, 1-12. https://doi.org/10.1016/j.tre.2013.09.005

Bunkley, N. (2015). Ford F-150 output pinched by frame shortage, workers say. Automotive News, May 29, 2015. http://www.autonews.com/article/20150529/OEM01/150529839/ford-f-150-output-pinched-by-frame-shortage-workers-

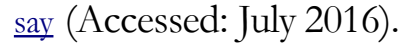

Cedillo-Campos, M., \& Perez-Araos, A. (2010). Hybrid supply chains in emerging markets: the case of the Mexican auto industry. South African Journal of Industrial Engineering, 21(1), 193-206. https://doi.org/10.7166/21-1-77

Cedillo-Campos, M., \& Gudiño, G. (2011). A Custom-made production system for emerging markets, (In Spanish). Interciencia, 36(6), 456-462.

Cedillo-Campos, M., Sanchez, C., Vadali, S., Villa, J., \& Menezes, M. (2014). Supply chain dynamics and the "cross-border effect:" The U.S.-Mexican border's case. Computers and Industrial Engineering, 72, 261-273. https://doi.org/10.1016/j.cie.2014.03.015

Cedillo-Campos, M., \& Cedillo-Campos, H. (2015). W@reRISK method: Security risk level classification of stock keeping units in a warehouse. Safety Science, 79, 358-368. https://doi.org/10.1016/j.ssci.2015.06.009

Chakraborty, A., \& Chatterjee, A. (2016). A surcharge pricing scheme for supply chain coordination under JIT environment. European Journal of Operational Research, 253(1), 14-24. https://doi.org/10.1016/j.ejor.2016.02.001

Chen, J.C., Chen, Y.Y., \& Liang, Y. (2016). Application of a genetic algorithm in solving the capacity allocation problem with machine dedication in the photolithography area. Journal of Manufacturing Systems, 41, 165-177. https://doi.org/10.1016/j.jmsy.2016.08.010

Chiang, C.Y., Lin, W.T., \& Suresh, N.C. (2016). An empirically-simulated investigation of the impact of demand forecasting on the bullwhip effect: Evidence from U.S. auto industry. International Journal of Production Economics, 117, 53-65. https://doi.org/10.1016/j.ijpe.2016.04.015

Diabat, A., \& Deskoores, R. (2016). A hybrid genetic algorithm based heuristic for an integrated supply chain problem. Journal of Manufacturing Systems, 38, 172-180. https://doi.org/10.1016/j.jmsy.2015.04.011

Dietrich, A.J., Kim, S., \& Sugunaram, V. (2007). A service-oriented architecture for mass customization a shoe industry case study. IEEE Transactions on Engineering Management, 4(1), 190-204. 
Doolen, T.L., \& Hacker, M.E. (2005). A review of lean assessment in organization: An exploratory study of lean practices by electronic manufacturers. Journal of Manufacturing Systems, 24(1), 55-67. https://doi.org/10.1016/S0278-6125(05)80007-X

Dubois, A., \& Gadde, L.E. (2002). Systematic combining: an abductive approach to case research. Journal of Business Research, 55(7), 553-560. https://doi.org/10.1016/S0148-2963(00)00195-8

ElMaraghy, H., Schuh, G., ElMaraghy, W., Piller, F., Schönsleben, P., Tseng, M. et al. (2013). Product variety management. CIRP Annals - Manufacturing Technology, (62), pp. 629-652. https://doi.org/10.1016/j.cirp.2013.05.007

Esmaeilian, B., Behdad, S., \& Wang, B. (2016). The evolution and future of manufacturing: A review. Journal of Manufacturing Systems, 39, 79-100. https://doi.org/10.1016/j.jmsy.2016.03.001

Graf, H. (2007). Innovative logistics is a vital part of transformable factories in the automotive industry. In Dashchenko, A.I. (Ed.). Reconfigurable manufacturing systems and transformable factories. Berlin: Springer: 423-457.

Green, K., Inman, A., Birouc, L., \& Whitten, D. (2014). Total JIT (T-JIT) and its impact on supply chain competency and organizational performance. International Journal of Production Economics, 147(Part A), 125-135. https://doi.org/10.1016/j.ijpe.2013.08.026

Gunner, H., Tunali, S., \& Jans R. (2010). A review of applications of genetic algorithms in lot sizing. Journal of Intelligent Manufacturing, 21(4), 575-590. https://doi.org/10.1007/s10845-008-0205-2

Heinecke, G., Köber, J., Lepratti, R., Lamparter, S., \& Kunz, A. (2012). Event-driven order rescheduling model for just-in-sequence deliveries to a mixed-model assembly line. Advances in Production Management Systems. Competitive Manufacturing for Innovative Products and Services, Volume 397 of the series IFIP Advances in Information and Communication Technology, 326-333.

Hüttmeir, A., de Treville, S., Van Ackere, A., Monnier, L., \& Prenninger, J. (2009). Trading off between heijunka and just-in-sequence. International Journal of Production Economics, 118(2), 501-507. https://doi.org/10.1016/j.ijpe.2008.12.014

Jianga, L., Wanga, Y., \& Yan, X. (2014). Decision and coordination in a competing retail channel involving a third-party logistics provider. Computers \& Industrial Engineering, 76, 109-121.

https://doi.org/10.1016/j.cie.2014.07.026 
Kincade, D.H., Regan, C., \& Gibson, F.Y. (2007). Concurrent engineering for product development in mass customization for the apparel industry. International Journal of Operations \& Production Management, 2(6), 627-649. https://doi.org/10.1108/01443570710750295

KPI Library (2016). Stock cover 2016. http://kpilibrary.com/kpis/stock-cover (Accessed: June 2016).

Kovács, G., \& Spens, K.M. (2005). Abductive reasoning in logistics research. International Journal of Physical Distribution \& Logistics Management, 35(2), 132 144. https://doi.org/10.1108/09600030510590318

Kumar, V. (2010). JIT based quality management: Concepts and implications in Indian context. International Journal of Engineering Science and Technology, 2(1), 40-50.

Kumar, V., Mishra, N., Chan, F.T., \& Verma, A. (2011). Managing warehousing in an agile supply chain environment: an F-AIS algorithm based approach. International Journal of Production Research, 49(21), 6407-6426. https://doi.org/10.1080/00207543.2010.528057

Kumar, V.N.S.A., Kumar, V., Brady, M., Garza-Reyes, J.A., \& Simpson, M. (2017). Resolving forwardreverse logistics multi-period model using evolutionary algorithms. International Journal of Production Economics, 183(Part B), 458-469. https://doi.org/10.1016/j.ijpe.2016.04.026

Lindner, K. (2008). Evaluierung von Strategien zur standardisierten Notversorgung von Justin-Sequence-Teileumfängen in der Motormontage der BMW Group [Evaluating strategies for the standardisation of contingency plans for JIS modules in the engine assembly of BMW]. Working paper 2008; Vienna University of Economics and Business.

Ludwig, C. \& Hogg, R. (2016). Audi adapts logistics for San José Chiapa. Automotive Logistics, 30 January. http://automotivelogistics.media/news/mexico-conference-audi-adapts-logistics-for-san-jose-chiapa (A c c e s s e d: July 2016).

Ludwig, C. (2016a). Volkswagen \& Audi in Mexico part 2: Everything in its right place. Automotive Logistics, 19 J $\quad \begin{array}{lllll}\text { u http://automotivelogistics.media/intelligence/volkswagen-audi-in-mexico-part-2-everything-in-its-right-place } & 1 & \text { y }\end{array}$ (Accessed: July 2016).

Ludwig, C. (2016b). Ford Mexico part 1: A landmark investment gradually coming into focus. Automotive Logistics, $1 \mathrm{July}$. http://automotivelogistics.media/intelligence/landmark-investment-gradually-coming-focus (Accessed: July 2016).

Ludwig, C. (2016c). Canada's metro supply chain buys emergency freight provider evolution time critical. Automotive Logistics, 5 April. http://automotivelogistics.media/news/canadas-metro-supply-chain-buys-emergency-freight-providerevolution-time-critical (Accessed: July 2016). 
Meissner, S. (2010). Controlling just-in-sequence flow-production. Logistics Research, 2(1), 45-53. https://doi.org/10.1007/s12159-010-0026-5

Memaria, A., Rahimb, A., Absic, N., Ahmad, R., \& Hassana, A. (2016). Carbon-capped distribution planning: a JIT perspective. Computers \& Industrial Engineering, 97, 111-127. https://doi.org/10.1016/j.cie.2016.04.015

Morones, D. (2011). Modelo de escenarios de decisión para envios de lotes fijos en inventarios con revisión periódica. M.Sc. Thesis. In Spanish. National Council of Science and Technology, COMIMSA, Saltillo, Mexico.

Moslehi, G., \& Mahnam, M. (2011). A Pareto approach to multi-objective flexible job- shop scheduling problem using particles warm optimization and local search. International Journal of Production Economics, 129(1), 14-22. https://doi.org/10.1016/j.ijpe.2010.08.004

OICA - Organisation Internationale des Constructeurs d'Automobiles (2016). Production Statistics 2015. http://www.oica.net/category/production-statistics/ (Accessed: July 2016).

Pelikan, M. (2010). Genetic Algorithms. Missouri Estimation of Distribution Algorithms Laboratory (MEDAL), Department of Mathematics and Computer Science; St. Louis, MO, 29P.

Poiger, M., \& Reiner, G. (2008). Gestaltung und Bewertung von Just-in-Sequence-Anlieferung in der Automobilindustrie [Design and evaluation of JIS delivery in the automotive industry]. In EngelhardtNowitzki, C., Nowitzki, O., \& Krenn, B. (Eds.). Praktische Anwendung der Simulation im Materialflussmanagement [Practical applications of material flow simulation]. Wiesbaden: Gabler, 133-143. https://doi.org/10.1007/978-3-8349-9806-4_9

Rosendahl, F., \& Radow, R. (2004). Produktionsendstufe für Motorra der [Final assembly for motorcycles]. In Wiendahl, H.P., Gerst, D. \& Keunecke, L. (Eds.). Variantenbeherrschung in der Montage [Variety management in production assemblies] 2004. Berlin: Springer, 191-207. https://doi.org/10.1007/978-3-642-18947-0_11

Sanchez, C., Cedillo-Campos, M., Martinez, J., \& Perez, P. (2011). Global economic crisis and Mexican automotive suppliers: impacts on the labor capital. Simulation: Transactions of the Society for Modeling and Simulation International, 87(8), 711-725. https://doi.org/10.1177/0037549710393259

Saracoglua, I., Topaloglub, S., \& Keskinturk, T. (2014). A genetic algorithm approach for multi-product multi-period continuous review inventory models. Expert Systems with Applications, 41(18), 8189-8202. https://doi.org/10.1016/j.eswa.2014.07.003 
Staeblein, T., \& Aoki, K. (2015). Planning and scheduling in the automotive industry: A comparison of industrial practice at German and Japanese makers. International Journal of Production Economics, 162, 258-272. https://doi.org/10.1016/j.ijpe.2014.07.005

Shi, Y., Zhang, A., Arthanari, T., Liu, Y., \& Cheng, T.E.C. (2016). Third-party purchase: An empirical study of third-party logistics providers in China. International Journal of Production Economics, 171, 189-200. https://doi.org/10.1016/j.ijpe.2015.08.028

Suyabatmaza, A., Altekinb, F., \& Şahin, G. (2014). Hybrid simulation-analytical modeling approaches for the reverse logistics network design of a third-party logistics provider. Computers \& Industrial Engineering, 70, 74-89. https://doi.org/10.1016/j.cie.2014.01.004

Thun, J.H., Drücke, M., \& Silveira-Camargos, V. (2007). Just in Sequence - Eine Erweiterung des Just in Time durch Sequenzzulieferung [Just-in-sequence - an expansion of just-in-time by sequence delivery]. Logistik Management, 9(4), 34-46.

Thun, J.H., Marble, R.P., \& Silveira-Camargos, V. (2007). A conceptual framework and empirical results of the risk and potential of just-in-sequence - a study of the German automotive industry. Journal of Operations and Logistics, 1(2), 1-13.

T'kindt, V. (2011). Multicriteria models for just-in-time scheduling. International Journal of Production Research, 49(11), 3191-3209. https://doi.org/10.1080/00207541003733783

Toth, M., Seidel, T., \& Klingebiel, K. (2008). Moving towards BTO - an engine case study. In Parry, G., \& Graves, A. (Eds.). Built to order - the road to the 5-day car. London: Springer. 297-310. https://doi.org/10.1007/978-1-84800-225-8_17

Trebilcock, B. (2006). Building a new supply chain. Modern Materials Handling, 61(1), 32.

Trentin, A., Forza, C., \& Perin, E. (2015). Embeddedness and path dependence of organizational capabilities for mass customization and green management: A longitudinal case study in the machinery industry. International Journal of Production Economics, 169, 253-276. https://doi.org/10.1016/j.ijpe.2015.08.011

Vörös, J., \& Rappai, G. (2016). Process quality adjusted lot sizing and marketing interface in JIT environment. Applied Mathematical Modelling, 40(13-14), 6708-6724. https://doi.org/10.1016/j.apm.2016.02.011

Wagner, S., \& Silveira-Camargos, V. (2011). Decision Model for the application of just-in-sequence. International Journal of Production Research, 49(19), 5713-5733. https://doi.org/10.1080/00207543.2010.505216 
Wagner, S., \& Silveira-Camargos, V. (2012). Managing risks in Just-In-Sequence supply networks: exploratory evidence from automakers. IEEE Transactions on Engineering Management, 59(1), 52-64. https://doi.org/10.1109/TEM.2010.2087762

Werner, S., Kellner, M., Schenk, E., \& Weigert, G. (2003). Just-in-sequence material supply - a simulation based solution in electronics production. Robotics \& Computer Integrated Manufacturing, 19(1/2), 107-111. https://doi.org/10.1016/S0736-5845(02)00067-4

Zhang, Y., \& Lam, J. (2016). Estimating economic losses of industry clusters due to port disruptions. Transportation Research Part A: Policy and Practice, 91, 17-33. https://doi.org/10.1016/j.tra.2016.05.017

Journal of Industrial Engineering and Management, 2017 (www.jiem.org)

Article's contents are provided on an Attribution-Non Commercial 3.0 Creative commons license. Readers are allowed to copy, distribute and communicate article's contents, provided the author's and Journal of Industrial Engineering and Management's names are included. It must not be used for commercial purposes. To see the complete license contents, please visit http://creativecommons.org/licenses/by-nc/3.0/. 